This peer reviewed manuscript has been accepted for publications to the Tribology Letters.

Cite this article as: M. Polajnar, M. Kalin, Effect of the slide-to-roll ratio and the contact kinematics on the elastohydrodynamic friction in diamond-like-carbon contacts with different wetting behaviours,

Tribology Letters 60 (2015) 1-10. DOI: https://doi.org/10.1007/s11249-015-0593-3

\title{
Effect of the Slide-to-Roll Ratio and the Contact Kinematics on the \\ Elastohydrodynamic friction in Diamond-Like-Carbon Contacts with \\ Different Wetting Behaviours
}

\author{
M. Polajnar ${ }^{\mathrm{a}}$ and M. Kalin ${ }^{\mathrm{a}, *}$ \\ ${ }^{a}$ University of Ljubljana, Laboratory for Tribology and Interface Nanotechnology, \\ Bogišičeva 8, 1000 Ljubljana, Slovenia \\ * Corresponding author. Tel.: +38614771 462; fax: +38614771 469; \\ E-mail address: mitjan.kalin@tint.fs.uni-lj.si.
}

\begin{abstract}
In this paper we show how the slide-to-roll ratio (SRR), the contact kinematics and the surface energy all have important effects on the elastohydrodynamic (EHD) friction. As reported previously, diamond-like-carbon (DLC) contacts of the type DLC/DLC provide the lowest coefficient of friction, in particular those DLC materials with the lowest surface energies (three different DLC coatings were used in this study). A friction reduction of up to $48 \%$, compared to a steel/steel contact, was obtained. A surprising new finding from this investigation is that the friction in DLC contacts is significantly reduced for high SRRs, i.e., a difference of up to $27 \%$ was measured in the DLC/DLC contacts when the SRR increased from 0.5 (rolling prevails) to 1.8 (sliding prevails). However, even more surprising is the effect of the SRR on the friction in mixed steel/DLC contacts, which is related to the contact design and its kinematics. We found that if the DLC is coated on the slower surface, a high SRR will not reduce the friction to any significant extent, typically about $5 \%$, and at most 13 $\%$, compared to steel/steel contacts. However, a significant friction reduction is observed
\end{abstract}


This peer reviewed manuscript has been accepted for publications to the Tribology Letters.

Cite this article as: M. Polajnar, M. Kalin, Effect of the slide-to-roll ratio and the contact kinematics on the elastohydrodynamic friction in diamond-like-carbon contacts with different wetting behaviours, Tribology Letters 60 (2015) 1-10. DOI: https://doi.org/10.1007/s11249-015-0593-3

when applying a low-surface-energy DLC coating to the faster surface - on average about 20 $\%$ and as high as $33 \%$. In this case (a high SRR and DLC on the faster surface) mixed steel/DLC surfaces can experience a very similar friction as that seen for DLC/DLC contacts. Qualitatively the same behaviour was found for both, positive and negative SRR values.

Keywords: EHD lubrication, DLC, surface energy, wetting, slide-to-roll ratio.

\section{List of symbols}

$u_{e} \ldots$ Entrainment speed, $\mathrm{mm} / \mathrm{s}$

$u_{s} \ldots$ Sliding speed, $\mathrm{mm} / \mathrm{s}$

$S R R$... Slide-to-roll ratio, /

$h_{0} \ldots$ Minimum film thickness, $\mu m$

$R^{\prime} \ldots$ Reduced radius of curvature, $m$

$E^{\prime} \ldots$ Reduced Young's modulus, $P a$

$\alpha \ldots$ Pressure-viscosity coefficient, $m^{2} / N$

$W \ldots$ Contact load, $N$

$k$... Ellipticity parameter, /

$\eta \ldots$ Dynamic viscosity, $c S t$

A... Area of ball-disc contact, $\mathrm{mm}^{2}$

$\lambda$... Tallian (Lambda) parameter, /

$R_{q D} \ldots$ Root mean square of disc roughness, $\mu m$

$R_{q B} \ldots$ Root mean square of ball roughness, $\mu m$ 
This peer reviewed manuscript has been accepted for publications to the Tribology Letters.

Cite this article as: M. Polajnar, M. Kalin, Effect of the slide-to-roll ratio and the contact kinematics on the elastohydrodynamic friction in diamond-like-carbon contacts with different wetting behaviours, Tribology Letters 60 (2015) 1-10. DOI: https://doi.org/10.1007/s11249-015-0593-3

\section{Introduction}

Various non-conformal, lubricated contacts (e.g., gears, roller bearings, cam followers) operate to a large extent in the elastohydrodynamic lubrication (EHL) regime. In these conditions there is a full-lubricating film that prevents any contact between the asperities of both surfaces within the contact, which is the desirable operating condition in terms of wear reduction and a lower or even negligible contribution of the solid-solid asperity contacts to the friction. However, in the EHL regime, viscous friction within the lubricating film plays an important role and defines the overall friction performance of the lubricated contact, making it one of the key tribological issues in EHL contacts. Recently, it was found that DLC coatings can offer a signifficant friction reduction in EHL contacts, when compared to steel contacts, without any other change in the oil or the contact's operating parameters [1-6]. Some recent studies using DLC coatings [1-4, 7], but also several previous studies with a variety of other types of materials and liquids [8-14], showed that the reduction in the friction is strongly affected by the wetting and the surface energy. However, in the past, inconsistencies were often noted with respect to the effect of these two parameters. This contradiction was recently explained by the need for a "spreading wetting" concept for oils, and the use of a spreading parameter as a measure of the wetting behaviour $[15,16]$, instead of the more commonly used contact angle. It was found that the coefficient of friction correlates much better with this newly derived spreading parameter than with the contact angle. Moreover, another signifficant and necessary parameter for a properly designed DLC lubricated contact was found to be the polar surface energy [4], rather than the total surface energy, which was exclusively used for these correlations until now.

On the other hand, thermal effects were also suggested as a possible reason for the DLC's friction reduction, since DLC typically possesses a lower thermal conductivity than steel, 
This peer reviewed manuscript has been accepted for publications to the Tribology Letters.

Cite this article as: M. Polajnar, M. Kalin, Effect of the slide-to-roll ratio and the contact kinematics on the elastohydrodynamic friction in diamond-like-carbon contacts with different wetting behaviours, Tribology Letters 60 (2015) 1-10. DOI: https://doi.org/10.1007/s11249-015-0593-3

which may reduce the viscosity and, as a consequence, the friction $[6,17]$. However, in addition to the suface energy, wetting and thermal conductivity $[1-4,6]$, additonal parameters or design rules that might further reduce the friction have not yet been reported. For example, contact kinematics and SRR should also play an important role in the tribological behaviour for the EHL regime, especially when considering a high or low shear of the fluid, i.e., whether the slide-to-roll ratio (SRR) is high or low. This is because sliding induces a much higher shear than rolling, and shear plays a crucial role in the rheology and the EHL friction regime [18]. However, past EHD studies indicated that friction can increase [19, 20], or decrease [2, 17]. For DLC contacts, Evans et al. reported some reduction in the traction coefficient in a study up to SRR 1.0 [2], while Björling et al. [6] concluded that there is neglegible difference in the coefficient of friction for mixed steel/DLC contacts, but they only used low SRR values of less than 0.5. Therefore, in view of recent findings about the wetting effect in EHL friction, the influences of the shear and the contact kinematics still need to be better explored and determined in order to maximise the effect of the newly proposed concepts of wetting and surface energy in friction behaviour and its tailoring $[5,16,17]$.

The last, but not least, important question that needs to be considered in relation to contact kinematics is which surface within the contact should possess the poorer wetting behaviour: the faster, the slower or it does not matter? This is especially important if the SRR, and thus the fluid velocity distribution within the EHD film, is changing signifficantly. Some previous studies investigated only self-mated DLC/DLC contacts [17], some only mixed steel/DLC contacts [2] and some both cases [1, 4, 6]; however, a significant effect of the SRR or the contact kinematic conditions on the friction has not yet been reported in a broad range of SRR 
This peer reviewed manuscript has been accepted for publications to the Tribology Letters.

Cite this article as: M. Polajnar, M. Kalin, Effect of the slide-to-roll ratio and the contact kinematics on the elastohydrodynamic friction in diamond-like-carbon contacts with different wetting behaviours,

Tribology Letters 60 (2015) 1-10. DOI: https://doi.org/10.1007/s11249-015-0593-3

values and by systematically controlling the DLC surface velocity and DLC position, related to contact geometry and wetting properties.

However, it seems to be intuitive that a larger variation of the SRR, together with a variation of the DLC coating's position within the contact (slower, faster and both surfaces) and also a larger variation of the DLC surafce energies should have a measurable effect on the friction. Accordingly, this was set as one of the goals of this study.

We used three different DLC coatings with a distinctive variation in the polar surface energies, which control the wetting behaviour $[15,16]$, and a broad range of SRR values $(0.5-$ 1.8 ) in the velocity region between $0.5-2.0 \mathrm{~m} / \mathrm{s}$, to find to what extent the position of the DLC coating within the contact is relavent and its effect on the elastohydrodynamic (EHD) friction. Selected tests were performed also to compare effects in positive and negative SRR regime.

\section{Experimental}

\subsection{Materials and oil}

The samples used in this study were standard, mini-traction-machine (MTM) test specimens, i.e., balls with a diameter of $19.05 \mathrm{~mm}$ and discs with a diameter of $46 \mathrm{~mm}$ (producer: PCS Instruments, London, United Kingdom) [21] made from DIN 100Cr6 steel (i.e., AISI 52100). The hardness of the steel balls and discs was 800-920 HV and 720-780 HV, respectively, as reported by the producer. On some of these samples we subsequently deposited selected DLC coatings.

Three DLC coatings with different structures and chemical compositions were chosen in order to provide different surface energies when wetting with the lubricating oil. We used non- 
This peer reviewed manuscript has been accepted for publications to the Tribology Letters.

Cite this article as: M. Polajnar, M. Kalin, Effect of the slide-to-roll ratio and the contact kinematics on the elastohydrodynamic friction in diamond-like-carbon contacts with different wetting behaviours, Tribology Letters 60 (2015) 1-10. DOI: https://doi.org/10.1007/s11249-015-0593-3

doped, hydrogenated, amorphous DLC (denoted as a-C:H) and two different fluorine-doped, hydrogenated, DLC coatings (denoted as F-DLC1 and F-DLC2). The a-C:H coating was a typical, standard, non-doped, hydrogenated, amorphous DLC coating with a $\mathrm{H}$ content of 30 at.\%. The first fluorine-doped DLC coating with a $\mathrm{H}$ content of 6 at.\% and a F content of 19 at.\% is denoted as F-DLC1. The second fluorine-doped DLC coating with a H content of 17 at. $\%$ and a F content of 12.5 at.\% is denoted as F-DLC2. The deposition process and the main properties of the used DLC coatings are reported elsewhere $[4,15,16]$.

The roughnesses ( $R_{a}$ and $R_{q}$ values) of all the test specimens (i.e., the balls and discs) were measured on a 3D optical microscope (Contour GT-Ko, Bruker) using white-light interferometry. The $\mathrm{R}_{\mathrm{a}}$ and $\mathrm{R}_{\mathrm{q}}$ values are reported in Table 1 . The roughnesses of the DLC specimens were slightly increased (compared to the steel surface) after the deposition of the coating.

A synthetic polyalphaolefin (PAO) base oil (Exxon Mobil, Houston, USA) was used as the lubricant. Its viscosity is $69.2 \mathrm{~mm}^{2} / \mathrm{s}$ at $40^{\circ} \mathrm{C}$ and $10.4 \mathrm{~mm}^{2} / \mathrm{s}$ at $100^{\circ} \mathrm{C}$, while its specific gravity is 0.836 at $15.6^{\circ} \mathrm{C}$, as reported by the producer [22]. No additives were included in the base oil.

\subsection{Surface energy}

The surface energies of the selected materials (i.e., the steel and the DLC coatings) were determined with the sessile drop technique (contact angle measurements) using the OwensWendt-Rabel-Kaelble (OWRK) method [23]. The procedure for obtaining the surface energies is described in detail in previous studies $[15,16]$. The tests were performed using a 
This peer reviewed manuscript has been accepted for publications to the Tribology Letters.

Cite this article as: M. Polajnar, M. Kalin, Effect of the slide-to-roll ratio and the contact kinematics on the elastohydrodynamic friction in diamond-like-carbon contacts with different wetting behaviours,

Tribology Letters 60 (2015) 1-10. DOI: https://doi.org/10.1007/s11249-015-0593-3

contact-angle goniometer (CAM 101, KSV Instruments, Helsinki, Finland) at ambient temperature $\left(21 \pm 1{ }^{\circ} \mathrm{C}\right)$. Prior to the contact-angle measurements, the surfaces were rinsed with high-purity ethanol and dried in a stream of hot air.

\subsection{Tribological tests}

All four selected materials (the steel and the three DLC coatings) were tested in four different types of contacts lubricated with the PAO oil. Denotation in this work is always ball/disc. The first type of the contact was a steel/steel contact, which served as a reference. The other three contacts involving DLC coatings were: DLC_slow/steel (ball coated with DLC), steel/DLC_fast (disc coated with DLC) and DLC/DLC (ball and disc coated with DLC). The coefficient of friction was monitored during the tests. All the tests were performed at ambient temperature, i.e., $21 \pm 1^{\circ} \mathrm{C}$, and repeated several times (average values and standard deviations are reported in the diagrams). The test specimens (balls and discs) were cleaned in the same way as for the contact-angle measurement (see section 2.2.) before each test. The normal loading force was $35 \mathrm{~N}$, corresponding to $1 \mathrm{GPa}$ of Hertzian contact pressure, while the entrainment velocity varied from $500 \mathrm{~mm} / \mathrm{s}$ to $2000 \mathrm{~mm} / \mathrm{s}$ (with steps of $100 \mathrm{~mm} / \mathrm{s}$ ). Each step lasted 30 seconds and the average value of the coefficient of friction was determined after reaching the steady-state value (usually after 2 seconds). The tests were performed at three different, positive SRRs, i.e., 0.5 (prevailing rolling conditions, Figure 1a), 1.0 (mixed rolling and sliding conditions, Figure 1b) and 1.8 (prevailing sliding conditions, Figure 1c) in order to simulate different contact-velocity conditions. The positive SRR value means that the disc velocity was always higher than the ball velocity, which in mixed steel/DLC contacts allows exactly the same contact conditions, with a variation of the surface properties only. Selected tests were performed also with the negative SRR of $-0.5,-1.0$ and -1.8 in order to 
This peer reviewed manuscript has been accepted for publications to the Tribology Letters.

Cite this article as: M. Polajnar, M. Kalin, Effect of the slide-to-roll ratio and the contact kinematics on the elastohydrodynamic friction in diamond-like-carbon contacts with different wetting behaviours, Tribology Letters 60 (2015) 1-10. DOI: https://doi.org/10.1007/s11249-015-0593-3

evaluate/exclude possible simultaneous effect of contact (sample) geometry and material properties on friction results. The SRR is defined as the ratio between the sliding and the entrainment velocity (see Figure 1), Equation (1).

$S R R=u_{s} / u_{e}$

In order to determine the lubrication regime the Tallian parameter was calculated [24], Equation (2).

$\lambda=\frac{h_{0}}{\sqrt{R_{q, b a l l}^{2}+R_{q, \text { disc }}^{2}}}$

The roughness values for the balls and discs in Equation (2) are reported in Table 1, while the minimum film thickness was calculated according to the set experimental parameters (load, speed, contact geometry, etc.) using the Hamrock-Dowson equation [25], Equation (3).

$\frac{h_{0}}{R^{\prime}}=3.63\left(\frac{u_{e} \eta_{0}}{E^{\prime} R^{\prime}}\right)^{0.68}\left(\alpha E^{\prime}\right)^{0.49}\left(\frac{W}{E^{\prime} R^{\prime 2}}\right)^{-0.073}\left(1-e^{-0.68 k}\right)$

From the calculated values for the Tallian parameter, which is always above 5, we can conclude that all the tests were performed in the EHD lubrication regime.

\section{Results}

\subsection{Surface energy}


This peer reviewed manuscript has been accepted for publications to the Tribology Letters.

Cite this article as: M. Polajnar, M. Kalin, Effect of the slide-to-roll ratio and the contact kinematics on the elastohydrodynamic friction in diamond-like-carbon contacts with different wetting behaviours,

Tribology Letters 60 (2015) 1-10. DOI: https://doi.org/10.1007/s11249-015-0593-3

The surface energies of selected surfaces are presented in Figure 2. The steel surface provides the highest surface energy, i.e., around $56 \mathrm{~mJ} / \mathrm{m}^{2}$. A slightly lower surface energy is provided by the a-C:H coating (i.e., $52 \mathrm{~mJ} / \mathrm{m}^{2}$ ), while the lowest surface energy is provided by both the fluorine-doped DLC coatings, i.e., F-DLC1, with a surface energy of approximately 45 $\mathrm{mJ} / \mathrm{m}^{2}$, and F-DLC2, with a surface energy of approximately $22 \mathrm{~mJ} / \mathrm{m}^{2}$. Furthermore, the a$\mathrm{C}: \mathrm{H}$ coating provides twice the lower polar component of surface energy $\left(7.6 \mathrm{~mJ} / \mathrm{m}^{2}\right)$, compared to the steel surface $\left(14.4 \mathrm{~mJ} / \mathrm{m}^{2}\right)$, while for the F-DLC1 coating the polar component of the surface energy is four times lower $\left(3.3 \mathrm{~mJ} / \mathrm{m}^{2}\right)$. The F-DLC2 coating has an almost negligible polar component of surface energy (below $1 \mathrm{~mJ} / \mathrm{m}^{2}$ ). In agreement with the above results, the selected DLC coatings provide poorer spreading wetting and weaker interactions with the lubricating oil due to the lower total surface energy and, especially, the lower polar surface energy, as described in detail elsewhere [4, 15].

\subsection{Coefficient of friction}

The coefficient of friction as a function of the entrainment speed and the SRR for different DLC coatings and variations of the contact kinematics, i.e., the position of the DLC coating for the slower, faster or both surfaces, is shown in Figure 3 to Figure 5. First, it should be noted that the coefficient of friction always decreases with an increase of the entrainment speed, irrespective of the SRR, the contact kinematics or the coating type, which is a wellknown thermal effect of the liquid shear thinning, and has been reported in many previous studies using this type of tribotester [2, 4, 26-29]. Furthermore, regardless of the DLC coating type (compare Figures 3-5) and the SRR (compare charts a-c within the same Figure) we can see that the highest coefficient of friction is always obtained in the steel/steel contact, while 
This peer reviewed manuscript has been accepted for publications to the Tribology Letters.

Cite this article as: M. Polajnar, M. Kalin, Effect of the slide-to-roll ratio and the contact kinematics on the elastohydrodynamic friction in diamond-like-carbon contacts with different wetting behaviours,

Tribology Letters 60 (2015) 1-10. DOI: https://doi.org/10.1007/s11249-015-0593-3

the DLC/DLC contacts always provide the lowest coefficient of friction. On the other hand, both contacts with one steel surface and one DLC surface, i.e., the DLC_slow/steel and the steel/DLC_fast, provide coefficient-of-friction values that are always just in between the steel/steel and the DLC/DLC contacts. These results are thus in agreement with previous studies on DLC coatings in the EHL regime $[1,4,6]$.

However, a comparison of the contacts where the DLC coating is on the slow surface (DLC_slow/steel contact) and the where DLC coating is on the fast surface (steel/DLC_fast contact) gives new, important information and an insight into the friction behaviour. Namely, the friction depends significantly on whether the DLC is coated on the slower or the faster surface within the contact, which is true for all DLC coatings (Figures $3-5$ ) and for a variety of SRR values (Figures a-c).

The effect of the SRR, however, depends on its magnitude. From Figures 3a, 4a and 5a, where the SRR is low, i.e., 0.5, we can see that there is a negligible difference in the coefficient of friction between the DLC_slow/steel and the steel/DLC_fast contacts (the curves almost overlap). On the other hand, when the SRR increases to 1.0 (see Figures $3 \mathrm{~b}, 4 \mathrm{~b}$ and $5 b$ ) the difference in the coefficient of friction between the DLC_slow/steel and the steel/DLC_fast contacts becomes significant. Finally, the difference in the friction for the mixed steel/DLC contacts becomes very pronounced and obvious when the SRR is very high, i.e., 1.8 (see Figures 3c, 4c and 5c). Moreover, at the highest SRR values the friction in the contacts with the slow DLC surface (DLC_slow/steel) becomes similar to the steel/steel, while in the contacts with the fast DLC (steel/DLC_fast) the friction becomes similar to the DLC/DLC values. 
This peer reviewed manuscript has been accepted for publications to the Tribology Letters.

Cite this article as: M. Polajnar, M. Kalin, Effect of the slide-to-roll ratio and the contact kinematics on the elastohydrodynamic friction in diamond-like-carbon contacts with different wetting behaviours, Tribology Letters 60 (2015) 1-10. DOI: https://doi.org/10.1007/s11249-015-0593-3

Figure 6a presents, for all three coating types (at an intermediate entrainment speed), the reduction in the friction relative to steel/steel contacts in the case when the DLC coating is on the slow surface (DLC_slow/steel), and in Figure 6b for the case when the DLC coating is on the fast surface (steel/DLC_fast). It is clear that having a DLC coating on the fast surface (Figure 6b) is much more effective, achieving a friction reduction of up to 33\%, compared to the opposite contact design (Figure $6 a$ ), where a maximum of only $13 \%$ can be obtained. The values depend on the coating type and the SRR, and can be almost negligible in the case of a slow DLC surface. Moreover, in the case of the DLC coating being on the slower surface (DLC_slow/steel) an increase in the SRR even has a negative effect on the friction reduction (see the decreasing trend in Figure 6a), while in the case of the DLC coating being on the faster surface (steel/DLC_fast) an increase in the SRR promotes a friction reduction (see the increasing trend in Figure 6b).

It should be noted, once again, that exactly the same phenomena were found for all three types of DLC coatings, i.e., a-C:H, F-DLC1 and F-DLC2. However, in agreement with our previous studies $[1,4]$, the lower the surface energy and the polar component of the surface energy of the DLC coatings, the lower is the coefficient of friction. This can be clearly seen in Figure $6 \mathrm{~b}$, where irrespective of the SRR values, the greatest friction reduction is observed for F-DLC2, followed by F-DLC1 and then a-C:H coating, in agreement with their surface energies, Figure 2.

Figure 7 shows, for self-mated steel/steel and DLC/DLC contacts (at an intermediate tested entrainment speed), how the polar surface energy and the SRR affect the friction in these EHD contacts. It is clear that, similar to the case of a fast DLC surface in a mixed 
This peer reviewed manuscript has been accepted for publications to the Tribology Letters.

Cite this article as: M. Polajnar, M. Kalin, Effect of the slide-to-roll ratio and the contact kinematics on the elastohydrodynamic friction in diamond-like-carbon contacts with different wetting behaviours,

Tribology Letters 60 (2015) 1-10. DOI: https://doi.org/10.1007/s11249-015-0593-3

steel/DLC_fast contact, the coefficient of friction decreases with a decrease of the polar surface energy and an increase in the SRR.

\section{Discussion}

Some new and very important findings relating to the friction behaviour in EHD contacts when using DLC coatings were obtained in this work. Moreover, earlier findings [1-4, 6, 17], that DLC coatings always reduce the EHD friction, which is the most pronounced if both surfaces in contact are coated (DLC/DLC) $[1,4,6,17]$, was confirmed.

(i) The effect of the SRR in a very wide range, i.e. from prevailing rolling ( $S R R=0.5)$ to prevailing sliding $(\mathrm{SRR}=1.8)$ contacts was investigated as a possible key design parameter to affect the EHD friction. While previous results with variation of SRR were not very explicit $[2,6,19,20]$, it turned out in this work (with variation in larger range) that SRR is very important DLC contact design parameter. This is true for all the DLC coatings used. It is clear that a higher SRR, meaning more sliding and more shear within the liquid (oil) itself and between the liquid and the surfaces, results in a larger friction reduction, which was up to 48 $\%$ for the DLC/DLC contacts (Figure 7) and $33 \%$ for the mixed steel/DLC contacts when the DLC was on the faster surface (Figure 6b). This finding agrees with the concept of poor interactions between the oil and the surface, if the polar surface energy is very low, which promotes slip at the interface due to a lack of the stronger polar surface forces [4]. This is similar to what we intuitively understand and see in everyday life, for example, on a Teflon (PTFE) pan surface with a water or oil droplet.

(ii) The second very important result from this work is that there is a proper contact design that will affect the EHD contacts when using surfaces with different wetting properties. This 
This peer reviewed manuscript has been accepted for publications to the Tribology Letters.

Cite this article as: M. Polajnar, M. Kalin, Effect of the slide-to-roll ratio and the contact kinematics on the elastohydrodynamic friction in diamond-like-carbon contacts with different wetting behaviours, Tribology Letters 60 (2015) 1-10. DOI: https://doi.org/10.1007/s11249-015-0593-3

is based on the fact that there is a significant impact on the friction when a low surface energy and poor-wetting DLC surface is coated on the faster or slower surface in the contact. Figure 6 show that the difference between the two contact designs (DLC on the faster or slower surface) is up to $22 \%$ at the highest SRR of 1.8 . For clarity, Figure 8 schematically plots the relative effect of the contact design by selecting the velocity of the poorly wetted (DLC) surface for controlling the EHD friction.

What is more, the results also show (Figures 3-5) that quite a significant friction reduction can be achieved, even in the steel/DLC contacts (not just DLC/DLC) - but only if the contact is properly designed, i.e., with the DLC on the faster surface. Namely, the steel/DLC_fast contacts (with a-C:H and F-DLC1) were only 5-7 \% less effective than the well-known and often-proved low-friction DLC/DLC contacts [1, 4, 6, 17]. However, this slightly lower efficiency in terms of the friction reduction of the steel/DLC_fast contacts may be cost effective in the case that DLC/DLC contacts are impractical, for example, due to geometrical restrictions. Although with the extreme friction-reducing coating, i.e., F-DLC2, the difference compared to DLC/DLC is slightly larger (about $15 \%$ ), this behaviour is still greatly pronounced and represents another significant technological and application relevant piece of information resulting from this study.

(iii) In relation to the effect of the SRR on the conditions and tribological performance in the EHL contacts, some earlier studies also pointed out the importance of positive and negative SRRs in the EHL, and a lower film thickness was observed with a negative than with a positive SRR [30]. Although it was concluded that the reason for the film-thickness asymmetry is unknown, and maybe attributed to the slip within the fluid or the thermal effects of the insulating glass disc (vs. steel ball), the thermal aspect was more elaborated. It was 
This peer reviewed manuscript has been accepted for publications to the Tribology Letters.

Cite this article as: M. Polajnar, M. Kalin, Effect of the slide-to-roll ratio and the contact kinematics on the elastohydrodynamic friction in diamond-like-carbon contacts with different wetting behaviours, Tribology Letters 60 (2015) 1-10. DOI: https://doi.org/10.1007/s11249-015-0593-3

calculated that when the conductive steel ball rotates at a very high, negative SRR, most of the frictional heat $(95 \%)$ transfers to it, which leads to the large isolating effect of the glass disc, with only $5 \%$ of heat dissipating into the isolating disc. It was thus hypothesized that this, in turn, affects a higher surface-temperature increase, and thus a larger viscosity decrease for a negative SRR than for a positive SRR, where the heat partitioning between the isolating disc and the steel ball is 50:50 [30]. This case is especially relevant for the current study since the reported heat conductivity of the glass was $1.5 \mathrm{~J} / \mathrm{mK}$, which is almost the same as a typical DLC coating [31-33]. Moreover, a similar hypothesis on the thermal aspects and a reduction of the viscosity, and consequently, a friction reduction due to the DLC isolating effect was also suggested recently by Björling et al. [17] for EHL contacts.

To verify this point in terms of the current study, we have performed a set of experiments with F-DLC2 by also using negative SRR values $(-0.5,-1.0$ and -1.8$)$, and as with the positive SRR, employing a variation of the DLC coating on both the ball and the disc. With this we have ensured all possible contact kinematics variations, with controlled and separate effects of the sample geometry and the wetting/surface energy, preventing possible systematic errors due to the test geometry, and not related to the surface material itself.

The results presented in Figure 9 provide very important findings. Namely, it should be stressed that, as with the positive SRR (Figure 5), when the negative SRR experiemtns were perfomed, the friction was also much lower when the DLC coating was on the faster surface, i.e., the ball in this case, than when the DLC was on the slower surface, i.e., on the disc (about $28 \%$ at $1.8 \mathrm{SRR}$, Figure 9c). This therefore proves that no matter whether the faster surface is the disc (Figure 5) or the ball (Figure 9) the friction is always lower on the fast DLC-coated surface. 
This peer reviewed manuscript has been accepted for publications to the Tribology Letters.

Cite this article as: M. Polajnar, M. Kalin, Effect of the slide-to-roll ratio and the contact kinematics on the elastohydrodynamic friction in diamond-like-carbon contacts with different wetting behaviours, Tribology Letters 60 (2015) 1-10. DOI: https://doi.org/10.1007/s11249-015-0593-3

These results, with the controlled and separated effect of the test geometry, the contact operating conditions and the DLC coating position, therefore directly show that the hypothesis of the thermal insulating effect, which is closely related to the contact (sample) geometry [30], is not the most decisive factor for friction reduction, rather the speed of the DLC surface prevails when determining the friction reduction.

Furthermore, Figure 9 also shows that, while a negative SRR typically provides a lower friction than a positive SRR (Figure 5), it is very obvious that with respect to the relative ranking among the different contact-material configurations, kinematics and SRR, the effect on the friction remains qualitatively exactly the same as with a positive SRR.

In addition, Figure 10 shows, for the same speed and SRR (absolute value), an almost 3-fold difference in the friction depending on the contact configuration, even with the same DLC coating, just depending on the contact design. What is more, these results also show that it is possible for mixed steel/DLC contacts with different kinematics and position of the DLC coating to achieve a lower friction with a positive SRR or negative SRR. Note that (3+) has a lower friction than (2-), and (3-) has a lower friction than (2+), Figure 10.

Accordingly, the contact configuration, with the proper selection of DLC coating on a faster surface with a high SRR thus ultimately prevails over the effect of a positive or negative SRR.

(iv) The final crucial parameter for friction reduction, which was suggested already in a previous study [4], is the wetting of the oil-surface interface and the (polar) surface energy of the DLC coatings being used. With the proper selection of the polar surface energy of the DLC coatings for a particular oil, where a low spreading parameter is obtained $[4,15]$, a substantial, up to $33 \%$, lower friction was measured in our study - only based on a selection of different DLC coatings. Although at present it is still not completely clear whether this 
This peer reviewed manuscript has been accepted for publications to the Tribology Letters.

Cite this article as: M. Polajnar, M. Kalin, Effect of the slide-to-roll ratio and the contact kinematics on the elastohydrodynamic friction in diamond-like-carbon contacts with different wetting behaviours,

Tribology Letters 60 (2015) 1-10. DOI: https://doi.org/10.1007/s11249-015-0593-3

effect is partly due to other phenomena, such as thermal effects $[6,17]$, the current experiments did not provide obvious supporting evidence for these, but show a good experimental correlation between the surface energy, the wetting and the friction force as with some other previous macro- $[1-4,8,10]$ and nano-scale $[13,14,34-37]$ studies.

To summarize, Figure 11 shows the composite effect on the friction of the whole range of parameters from this study, including the SRR, the polar surface energy and the contact design, separately for mixed steel/DLC (figure 11a) and self-mated DLC/DLC (figure 11b) contacts. The results in Figure 11a clearly show the advantage in terms of friction reduction of having a coated faster instead of slower surface in mixed steel/DLC contacts, which is at the same time promoted with a higher SRR. The effect of the DLC polar surface energy is also well illustrated, and is even more obvious in the DLC/DLC contacts, see Figure $11 \mathrm{~b}$.

\section{Conclusions}

1. DLC/DLC contacts provide the lowest coefficient of friction, with reductions as large as $48 \%$ vs. steel/steel being obtained.

2. The SRR was found to be a relevant design parameter for the reduction of friction. A reduction of up to $27 \%$ in the coefficient of friction was measured in the DLC/DLC contacts when the SRR increased from 0.5 to 1.8 .

3. A proper contact design has a significant impact on the friction for mixed steel/DLC contacts, showing that when a poor wetting surface is coated on a faster surface (instead of on a slower one) an up to $22 \%$ lower coefficient of friction is observed for high SRR values. 
This peer reviewed manuscript has been accepted for publications to the Tribology Letters.

Cite this article as: M. Polajnar, M. Kalin, Effect of the slide-to-roll ratio and the contact kinematics on the elastohydrodynamic friction in diamond-like-carbon contacts with different wetting behaviours, Tribology Letters 60 (2015) 1-10. DOI: https://doi.org/10.1007/s11249-015-0593-3

4. A significant friction reduction can be achieved if the mixed steel/DLC contact is properly designed. A steel/DLC_fast contact can be as little as 5-7\% less effective than a DLC/DLC contact, and thus may be a practical alternative in situations where a DLC/DLC contact is not possible.

5. The wetting of the oil-surface interface and the (polar) surface energy of the DLC are crucial parameters for friction reduction. An up to $33 \%$ lower friction was measured in our study - based only on the selection of different DLC coatings.

6. Qualitatively the same phenomena are observed in both positive and negative SRR regimes. Moreover, for mixed steel/DLC contacts with different kinematics and position of the DLC coating it is possible to achieve a lower friction with a positive SRR or negative SRR. 
This peer reviewed manuscript has been accepted for publications to the Tribology Letters.

Cite this article as: M. Polajnar, M. Kalin, Effect of the slide-to-roll ratio and the contact kinematics on the elastohydrodynamic friction in diamond-like-carbon contacts with different wetting behaviours, Tribology Letters 60 (2015) 1-10. DOI: https://doi.org/10.1007/s11249-015-0593-3

\section{References}

[1] Kalin, M., Velkavrh, I., Vižintin, J.: The Stribeck curve and lubrication design for nonfully wetted surfaces. Wear 267, 1232-1240 (2009)

[2] Evans, R.D., Cogdell, J.D., Richter, G.A., Doll, G.L.: Traction of Lubricated Rolling Contacts between Thin-Film Coatings and Steel. Tribol. T. 52, 106-113 (2009)

[3] Jahanmir, S., Hunsberger, A.Z., Heshmat, H.: Load Capacity and Durability of H-DLC Coated Hydrodynamic Thrust Bearings. J. Tribol. 133, 10p (2011)

[4] Kalin, M., Polajnar M.: The Effect of Wetting and Surface Energy on the Friction and Slip in Oil-Lubricated Contacts. Tribol. Lett. 52, 185-194 (2013)

[5] Kalin, M., Velkavrh, I.: Non-conventional inverse-Stribeck-curve behaviour and other characteristics of DLC coatings in all lubrication regimes. Wear 297, 911-918 (2013)

[6] Björling, M., Isaksson, P., Marklund, P., Larsson, R.: The Influence of DLC Coating on EHL Friction Coefficient. Tribol. Lett. 47, 285-294 (2012)

[7] Yamaguchi, T., Ando, J., Tsuda, T., Tajahashi, N., Tohyama, M., Murase, A., Ohmori, T., Hokkirigawa, K.: Sliding velocity dependency of the friction coefficient of Si-containing diamond-like carbon film under oil lubricated condition. Trib. Int. 44(11), 1296-1303 (2011). [8] Fu, Z., Wong, P.L., Guo, F.: Effect of Interfacial Properties on EHL Under Pure Sliding Conditions. Tribol. Lett. 49, 31-38 (2013)

[9] Li, X.M., Guo, F., Wong, P.L.: Shear rate and pressure effects on boundary slippage in highly stressed contacts. Tribol. Int. 59, 147-153 (2013)

[10] Liu, S., Luo, S., Li, G., Zhang, C., Lu, X.: Effect of surface physicochemical properties on the lubricating properties of water film. Appl. Surf. Sci. 254(22), 7137-7142 (2008).

[11] Choo, J.H., Spikes, H.A., Ratoi, M., Glovnea, R., Forrest, A.: Friction reduction in lowload hydrodynamic lubrication with a hydrophobic surface. Tribol. Int. 40, 154-159 (2007) 
This peer reviewed manuscript has been accepted for publications to the Tribology Letters.

Cite this article as: M. Polajnar, M. Kalin, Effect of the slide-to-roll ratio and the contact kinematics on the elastohydrodynamic friction in diamond-like-carbon contacts with different wetting behaviours, Tribology Letters 60 (2015) 1-10. DOI: https://doi.org/10.1007/s11249-015-0593-3

[12] Guo, F., Yang, S.Y., Ma, C., Wong, P.L.: Experimental Study on Lubrication Film Thickness Under Different Interface Wettabilities. Trib. Lett. 54(1), 81-88 (2014).

[13] Hild, W., Opitz, A., Schaefer, J.A., Scherge, M.: The effect of wetting on the microhydrodynamics of surfaces lubricated with water and oil. Wear 254, 871-875 (2003)

[14] Leong, J., Reddyhoff, T., Sinha, S.K., Holmes, A.S., Spikes, H.A.: Hydrodynamic Friction Reduction in a MAC-Hexadecane Lubricated MEMS Contact. Trib. Lett. 49(1), 217225 (2013).

[15] Kalin, M., Polajnar, M.: The correlation between the surface energy, the contact angle and the spreading parameter, and their relevance for the wetting behaviour of DLC with lubricating oils. Tribol. Int. 66, 225-233 (2013)

[16] Kalin, M., Polajnar, M.: The wetting of steel, DLC coatings, ceramics and polymers with oils and water: the importance and correlations of surface energy, surface tension, contact angle and spreading. Appl. Surf. Sci. 293, 97-108 (2014).

[17] Björling, M., Habchi, W., Bair, S., Larsson, R., Marklund, P.: Friction reduction in elastohydrodynamic contacts by thin-layer thermal insulation. Tribol. Lett. 53, 477-486 (2014)

[18] Spikes, H., Jie, Z.: History, origins and prediction of elastohydrodynamic friction. Trib. Lett. 56(1), 1-25 (2014).

[19] Ali, F., Hartl, M.: Friction of non-conformal contacts under starved EHD lubrication, MM Science Journal 376-277 (2012).

[20] Lafont Morgado, P., Echávarri Otero, J., Sánchez-Penuela Lejarraga, J.B., Munoz Sanz, J.L., Diaz Lantada, A., Munoz-Guijosa, J.M., Lorenzo Yustos, H., Leal Wina, P., Munoz Garcia, J.: Model for predicting friction coefficient and parameters with influence in 
This peer reviewed manuscript has been accepted for publications to the Tribology Letters.

Cite this article as: M. Polajnar, M. Kalin, Effect of the slide-to-roll ratio and the contact kinematics on the elastohydrodynamic friction in diamond-like-carbon contacts with different wetting behaviours, Tribology Letters 60 (2015) 1-10. DOI: https://doi.org/10.1007/s11249-015-0593-3

elastohydrodynamic lubrication, Proc. IMechE. Part J: J. Engineering Tribology 233 (2009) 949-958.

[21] Certificate of MTM Standard Specimen Pack (Batch Ref: B and 20371), PCS Instruments, London, UK, Supply date: 20.12.2012

[22] Certificate of analysis - Spectrasyn 10 (Batch No.: USRC 587), ExxonMobil Oil Corporation - Synthetics, Houston, USA, Supply date: 1.11.2012

[23] Owens, D.K., Wendt, R.C.: Estimation of the surface free energy of polymers. J. Appl. Polym. Sci. 13(8), 1741-1747 (1969)

[24] Tallian, T.E.: On competing failure modes in rolling contact. ASLE Trans. 10(4), 418439 (1967).

[25] Hamrock, B.J., Dowson, D.: Isothermal elastohydrodynamic lubrication of point contacts. Part III. Fully flooded results. J. Lubric. Tech.-T. ASME 99, 264-276 (1977)

[26] Gunsel, S., Koreck, S., Smeeth, M., Spikes, H.A.: The Elastohydrodynamic Friction and Film Forming Properties of Lubricant Base Oils. Tribol. T. 42, 559-569 (1999)

[27] Lafountain, A.R., Johnston, G.J., Spikes, H.A.: The Elastohydrodynamic Traction of Synthetic Base Oil Blends. Tribol. T. 44, 648-656 (2001)

[28] Björling, M., Habchi, W., Bair, S., Larsson, R., Marklund, P.: Towards the true prediction of EHL friction. Trib. Int. 66, 19-26 (2013)

[29] Björling, M., Larsson, R., Marklund, P., Kasseldt, E.: EHL friction mapping-the influence of lubricant, roughness, speed and slide to roll ratio. Proc. Inst. Mech. Eng. J J. Eng. Tribol. 225, 671-681 (2011)

[30] Smeeth M., Spikes H.A.: The influence of slide/roll ratio on the film thikcness of an EHD contact operation within mixed lubrication regime, Proc. 22nd Leeds-Lyon Symp., 695703 (1996). 
This peer reviewed manuscript has been accepted for publications to the Tribology Letters.

Cite this article as: M. Polajnar, M. Kalin, Effect of the slide-to-roll ratio and the contact kinematics on the elastohydrodynamic friction in diamond-like-carbon contacts with different wetting behaviours, Tribology Letters 60 (2015) 1-10. DOI: https://doi.org/10.1007/s11249-015-0593-3

[31] Wojciechowski, K.T., Zybala, R., Mania, R.: Application of DLC layers in 3-omega thermal conductivity method, Journal of Axhievements in Materials and Manufacturing Engineering, 37 (2009) 512-517.

[32] Shamsa, M., Liu, W.L., Balandin, A.A., Casiraghi, C., Milne, W.I., Ferrari, A.C.: Thermal conductivity of diamond-like carbon films, Appl. Phys. Lett. 89 (2006) 161921.

[33] Kim, J.W., Yang, H.-S., Jun, Y.H., Kim, K.C.: Interfacial effect on thermal conductivity of diamond-like carbon films, J. Mech. Sci. Technol. 24 (2010) 1511-1514.

[34] Ponjavic, A., Wong, J.S.: The effect of boundary slip on elastohydrodynamic lubrication. RSC Advances 4(40), 20821-20829 (2014)

[35] Choi, C.-H., Ulmanella, U., Kim, J. Ho, C.-M., Kim, C.-J.: Effective slip and friction reduction in nanograted superhydrophobic microchannels. Phys. Fluids 18, 087105 1-8 (2006) [36] Vinogradova, O. I.: Drainage of thin liquid film confined between hydrophobic surfaces. Langmuir 11, 2213-2220 (1995)

[37] Vinogradova, O. I.: Slippage of water over hydrophobic surfaces. Int. J. Miner. Process. $56,31-60(1999)$ 
This peer reviewed manuscript has been accepted for publications to the Tribology Letters.

Cite this article as: M. Polajnar, M. Kalin, Effect of the slide-to-roll ratio and the contact kinematics on the elastohydrodynamic friction in diamond-like-carbon contacts with different wetting behaviours, Tribology Letters 60 (2015) 1-10. DOI: https://doi.org/10.1007/s11249-015-0593-3

Table 1: Roughness of the MTM test specimens.

\begin{tabular}{|c|c|c|c|c|c|}
\hline Surface & Roughness & steel & a-C:H & F-DLC1 & F-DLC2 \\
\hline \multirow{2}{*}{ Ball } & $\mathrm{Ra}, \mu \mathrm{m}$ & $0.013 \pm 0.003$ & $0.030 \pm 0.007$ & $0.022 \pm 0.004$ & $0.037 \pm 0.009$ \\
\cline { 2 - 6 } & $\mathrm{Rq}, \mu \mathrm{m}$ & $0.018 \pm 0.005$ & $0.040 \pm 0.010$ & $0.032 \pm 0.0009$ & $0.047 \pm 0.011$ \\
\hline \multirow{2}{*}{ Disc } & $\mathrm{Ra}, \mu \mathrm{m}$ & $0.012 \pm 0.003$ & $0.019 \pm 0.005$ & $0.023 \pm 0.004$ & $0.019 \pm 0.004$ \\
\cline { 2 - 6 } & $\mathrm{Rq}, \mu \mathrm{m}$ & $0.015 \pm 0.003$ & $0.023 \pm 0.008$ & $0.032 \pm 0.006$ & $0.025 \pm 0.005$ \\
\hline
\end{tabular}

(a)

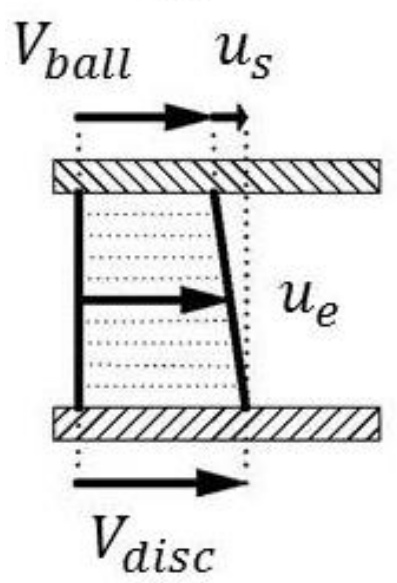

(b)

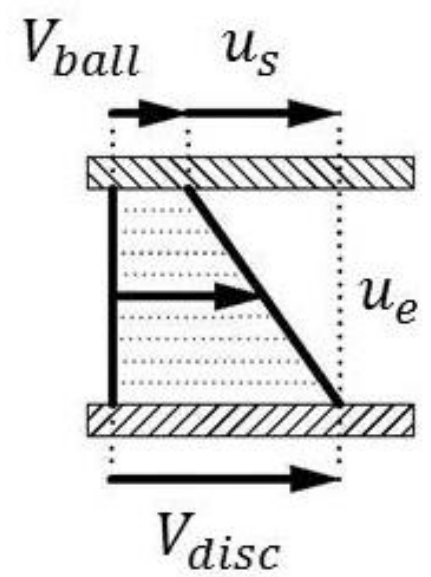

(c)

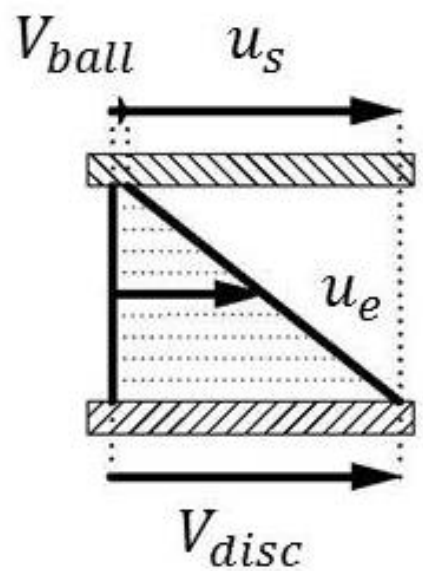

Fig. 1 Velocity profiles for lubricated contacts at the same entrainment speed $\left(u_{e}\right)$ of the lubricant, but with different slide-to-roll ratios (SRRs): (a) SRR=0.5, (b) SRR=1.0 and (c)

$$
\mathrm{SRR}=1.8 .
$$

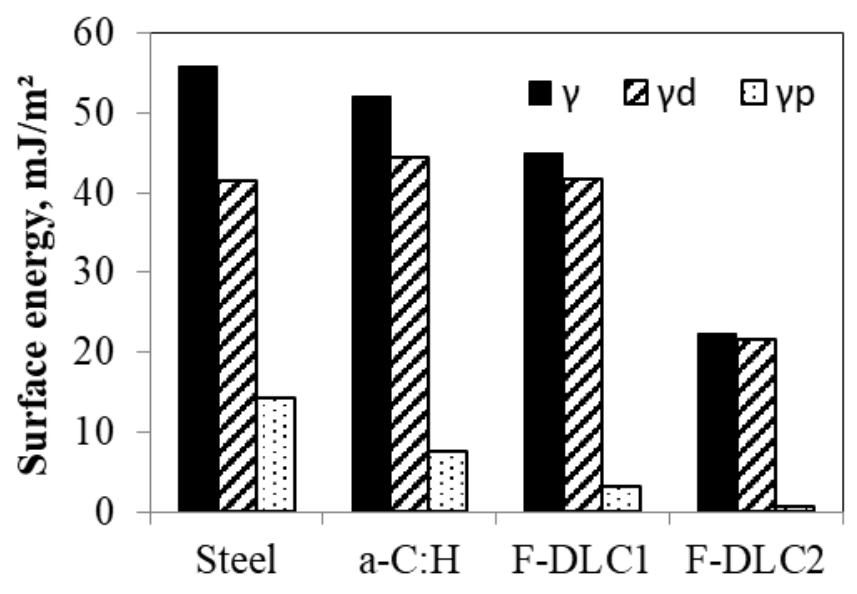

Fig. 2 Surface energies of the surfaces used. 
This peer reviewed manuscript has been accepted for publications to the Tribology Letters.

Cite this article as: M. Polajnar, M. Kalin, Effect of the slide-to-roll ratio and the contact kinematics on the elastohydrodynamic friction in diamond-like-carbon contacts with different wetting behaviours, Tribology Letters 60 (2015) 1-10. DOI: https://doi.org/10.1007/s11249-015-0593-3
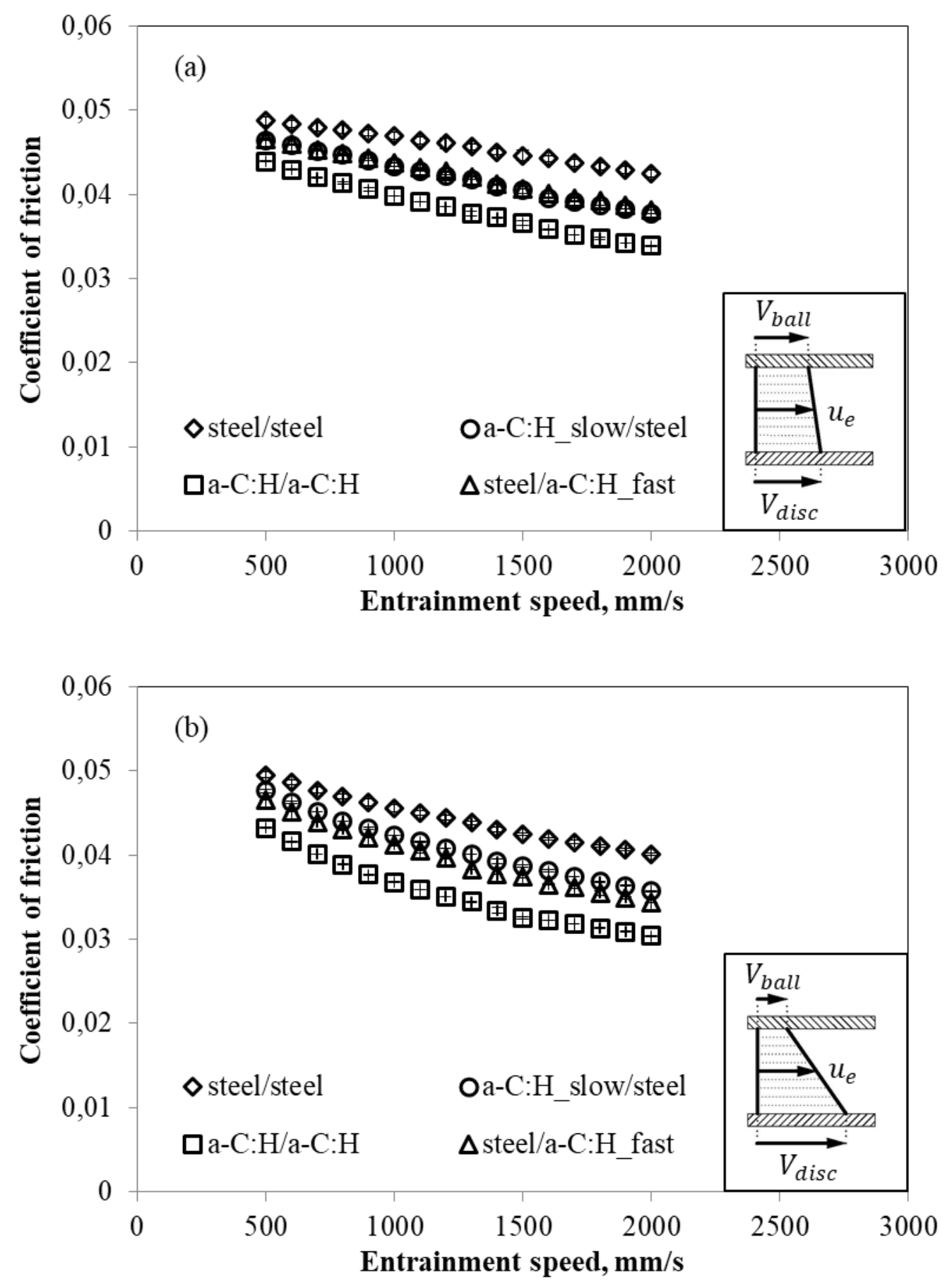
This peer reviewed manuscript has been accepted for publications to the Tribology Letters.

Cite this article as: M. Polajnar, M. Kalin, Effect of the slide-to-roll ratio and the contact kinematics on the elastohydrodynamic friction in diamond-like-carbon contacts with different wetting behaviours, Tribology Letters 60 (2015) 1-10. DOI: https://doi.org/10.1007/s11249-015-0593-3

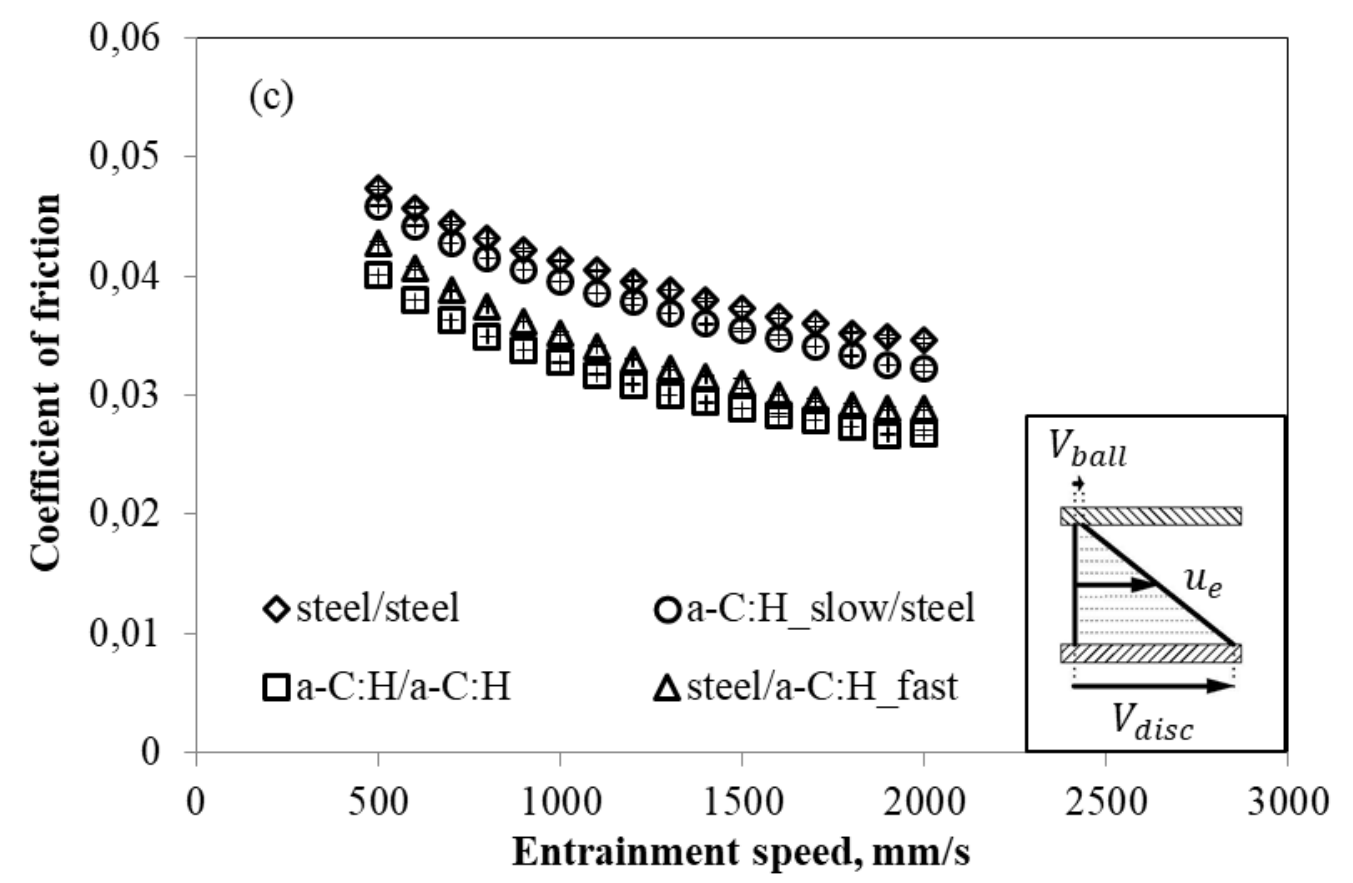

Fig. 3 Coefficient-of-friction results for the contacts of a-C:H coating at: (a) $S R R=0.5$, (b) $\mathrm{SRR}=1.0$ and (c) $\mathrm{SRR}=1.8$. The set of results for the steel/steel contact is always added as a reference and for a comparison.

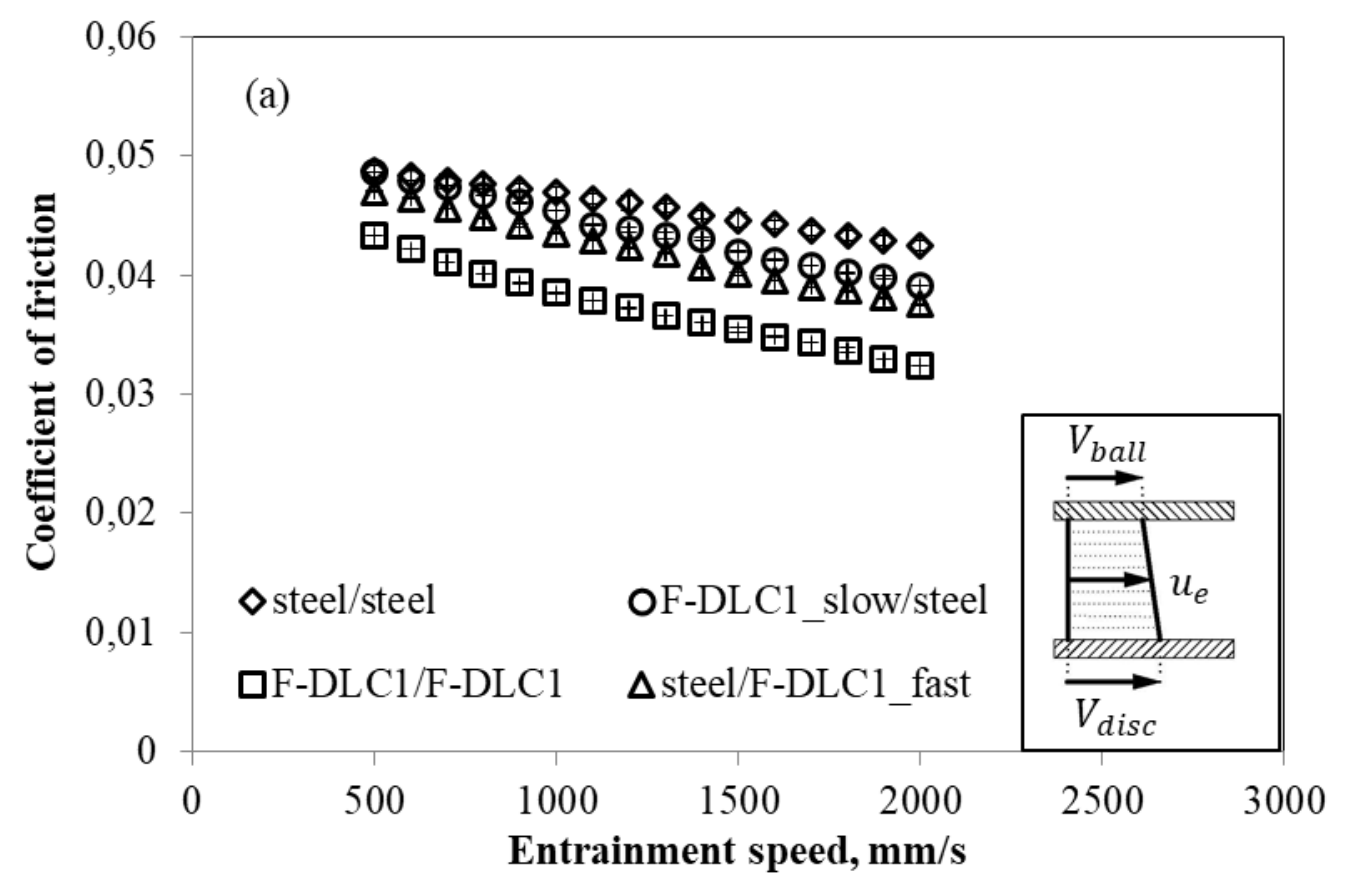


This peer reviewed manuscript has been accepted for publications to the Tribology Letters.

Cite this article as: M. Polajnar, M. Kalin, Effect of the slide-to-roll ratio and the contact kinematics on the elastohydrodynamic friction in diamond-like-carbon contacts with different wetting behaviours, Tribology Letters 60 (2015) 1-10. DOI: https://doi.org/10.1007/s11249-015-0593-3
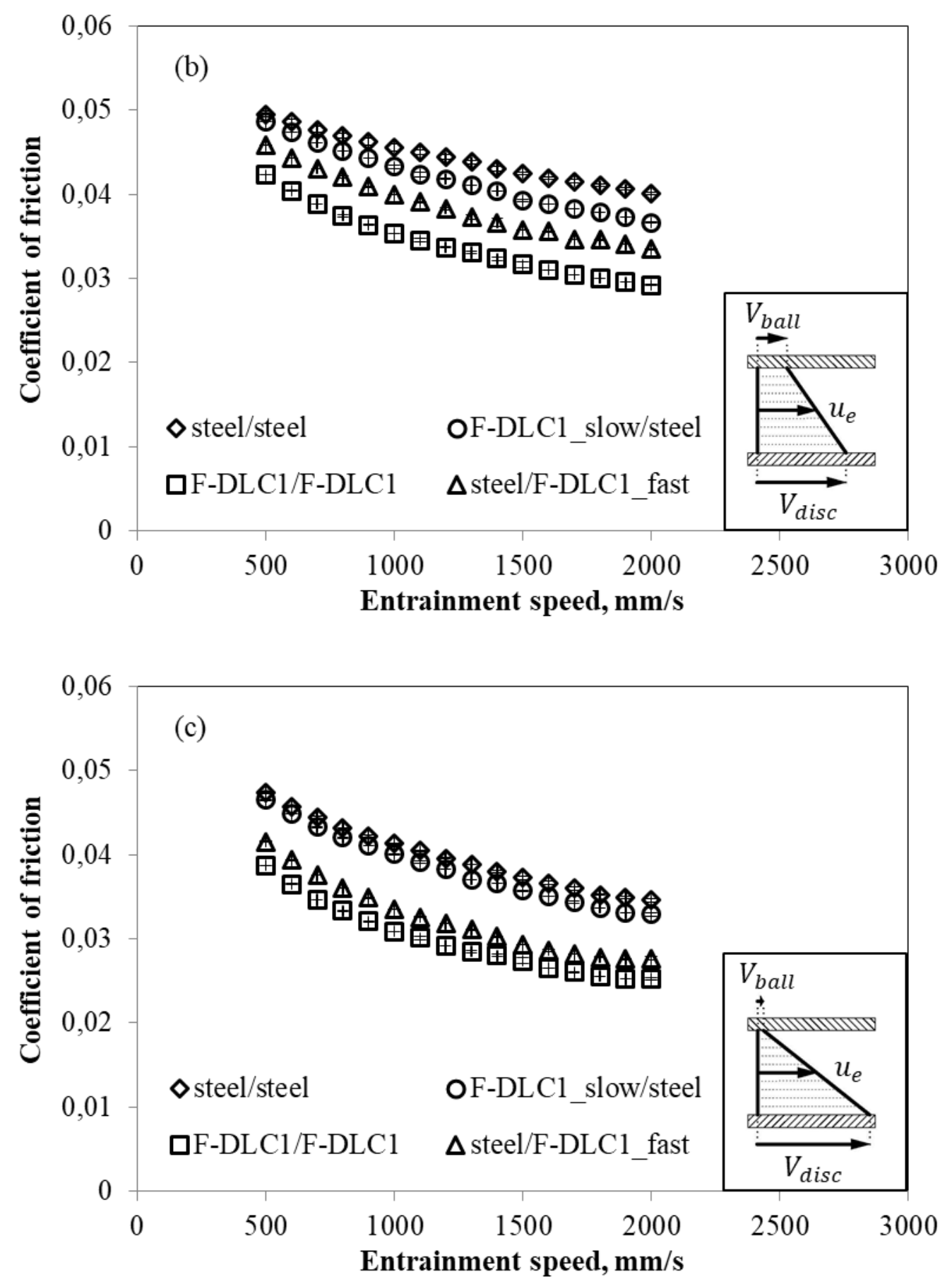

Fig. 4 Coefficient-of-friction results for contacts of F-DLC1 coating at: (a) SRR=0.5, (b) $\mathrm{SRR}=1.0$ and (c) $\mathrm{SRR}=1.8$. The set of results for the steel/steel contact is always added as a reference and for a comparison. 
This peer reviewed manuscript has been accepted for publications to the Tribology Letters.

Cite this article as: M. Polajnar, M. Kalin, Effect of the slide-to-roll ratio and the contact kinematics on the elastohydrodynamic friction in diamond-like-carbon contacts with different wetting behaviours, Tribology Letters 60 (2015) 1-10. DOI: https://doi.org/10.1007/s11249-015-0593-3
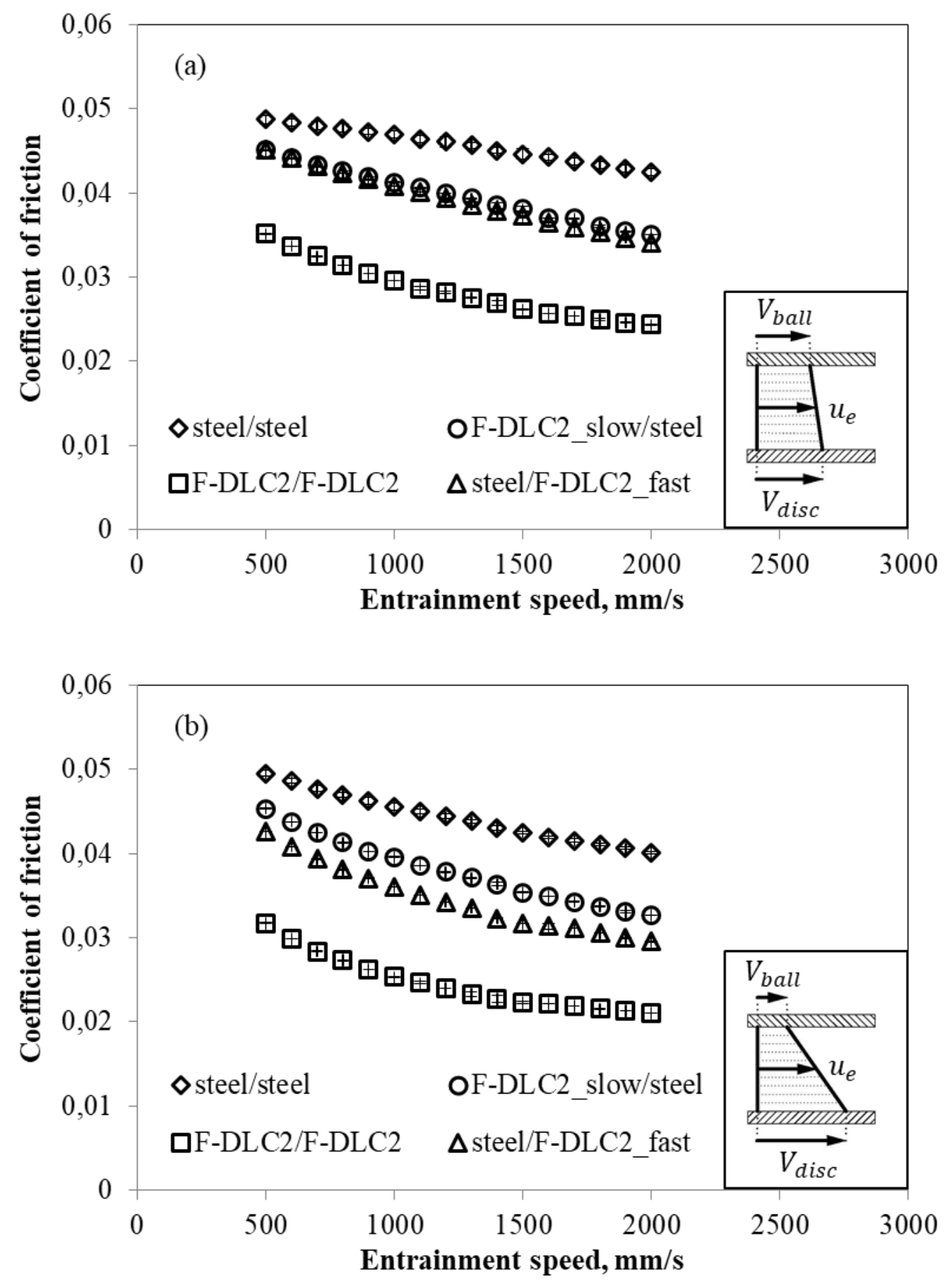
This peer reviewed manuscript has been accepted for publications to the Tribology Letters.

Cite this article as: M. Polajnar, M. Kalin, Effect of the slide-to-roll ratio and the contact kinematics on the elastohydrodynamic friction in diamond-like-carbon contacts with different wetting behaviours, Tribology Letters 60 (2015) 1-10. DOI: https://doi.org/10.1007/s11249-015-0593-3

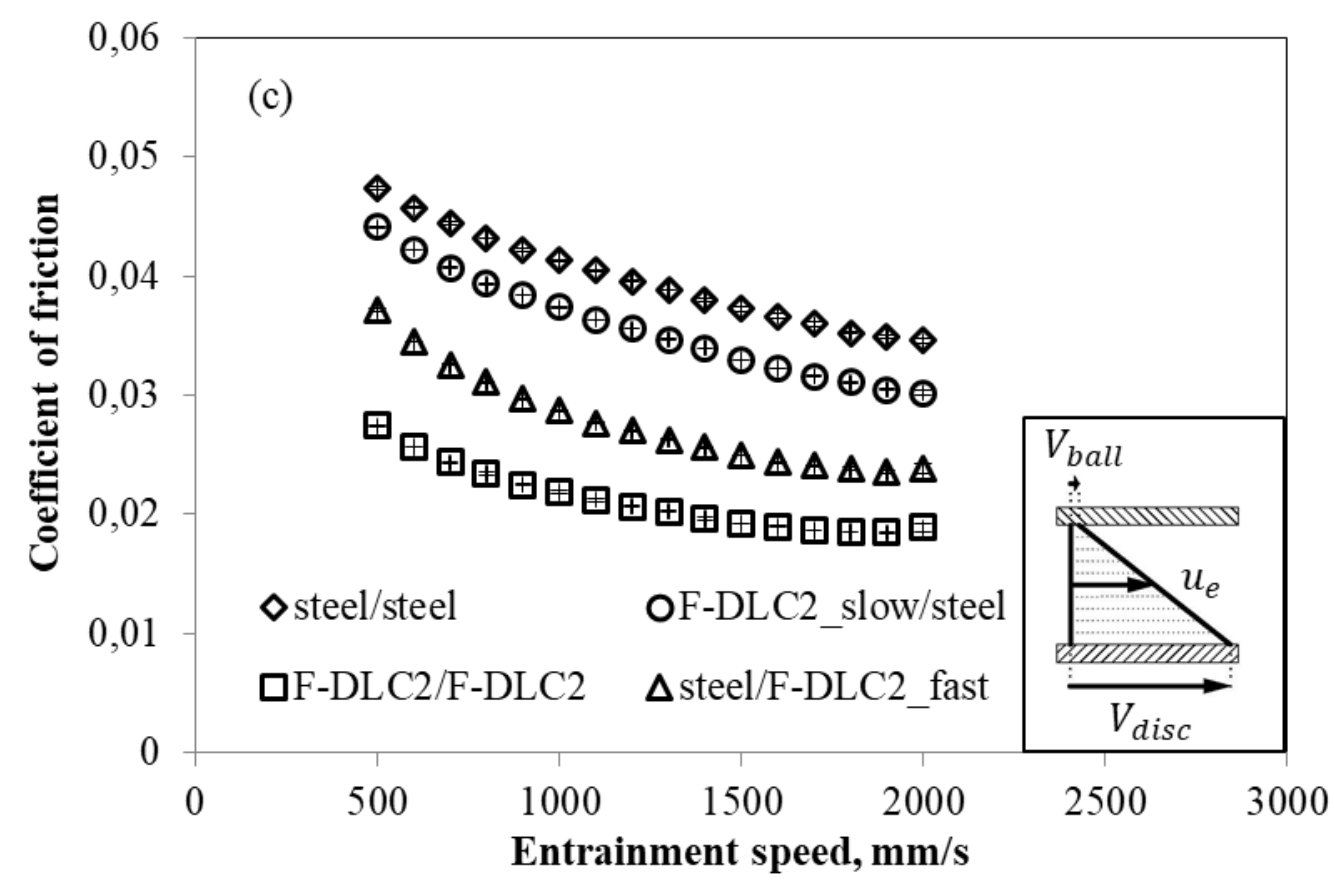

Fig. 5 Coefficient-of-friction results for contacts of F-DLC2 coating at: (a) SRR=0.5, (b) $\mathrm{SRR}=1.0$ and (c) $\mathrm{SRR}=1.8$. The set of results for steel/steel contact is always added as a reference and for a comparison. 
This peer reviewed manuscript has been accepted for publications to the Tribology Letters.

Cite this article as: M. Polajnar, M. Kalin, Effect of the slide-to-roll ratio and the contact kinematics on the elastohydrodynamic friction in diamond-like-carbon contacts with different wetting behaviours, Tribology Letters 60 (2015) 1-10. DOI: https://doi.org/10.1007/s11249-015-0593-3

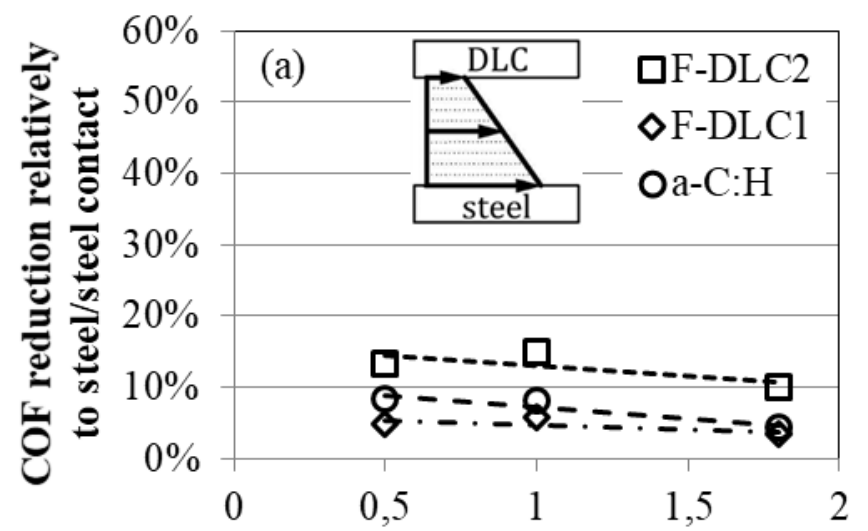

Slide-to-roll ratio

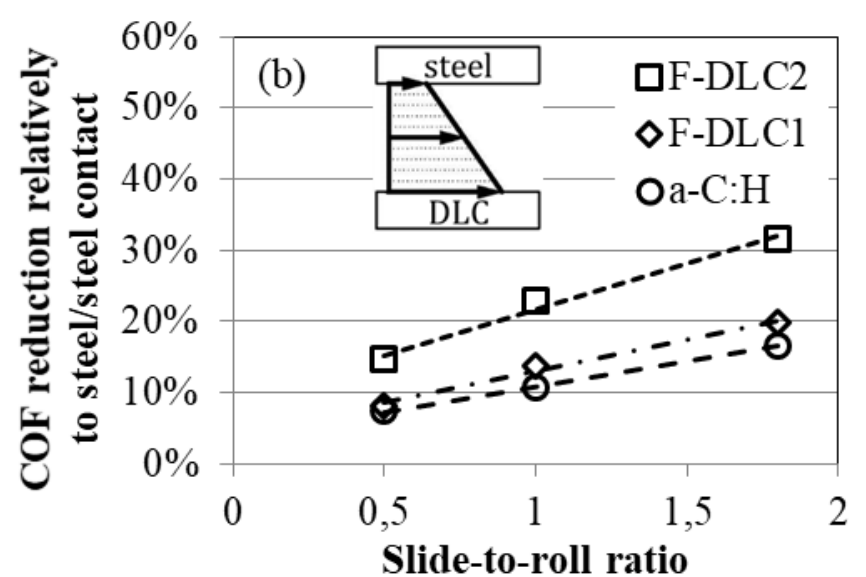

Fig. 6 Relative decrease in the coefficient of friction in the case of mixed steel/DLC contacts compared to a steel/steel contact (at entrainment speed of $1200 \mathrm{~mm} / \mathrm{s}$ ) for: (a) DLC_slow/steel and (b) steel/DLC_fast contacts.

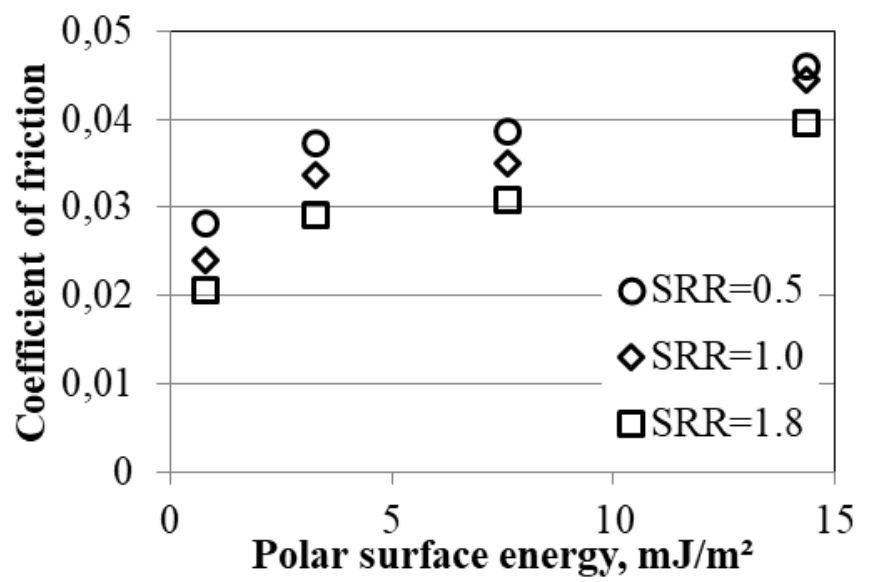


This peer reviewed manuscript has been accepted for publications to the Tribology Letters.

Cite this article as: M. Polajnar, M. Kalin, Effect of the slide-to-roll ratio and the contact kinematics on the elastohydrodynamic friction in diamond-like-carbon contacts with different wetting behaviours, Tribology Letters 60 (2015) 1-10. DOI: https://doi.org/10.1007/s11249-015-0593-3

Fig. 7 Coefficient of friction as a function of SRR and the polar surface energy (at an entrainment speed of $1200 \mathrm{~mm} / \mathrm{s}$ ) for self-mated steel/steel and DLC/DLC contacts.

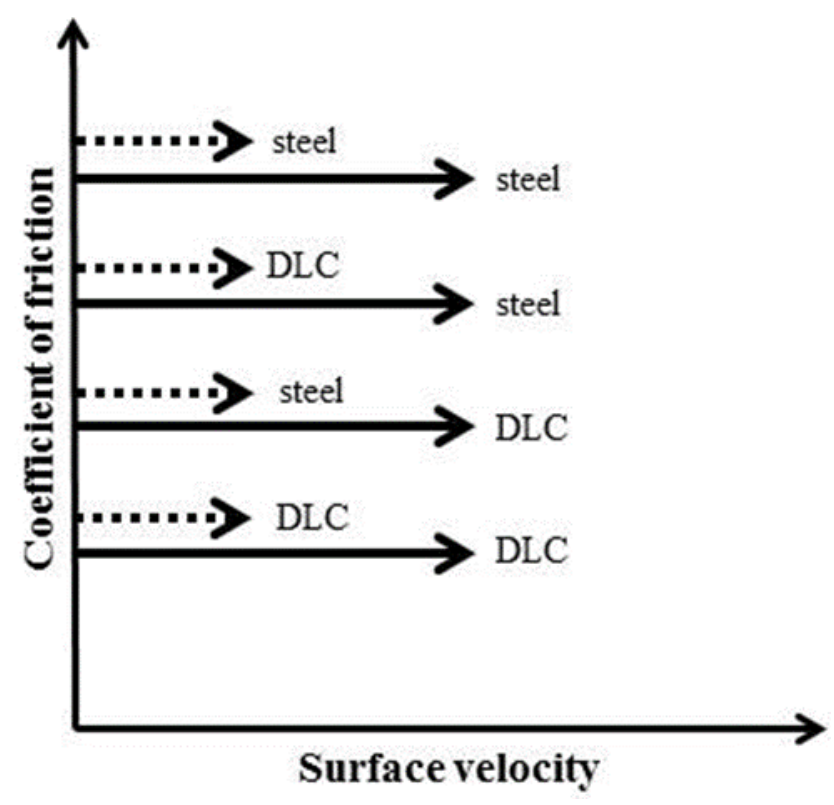

Fig. 8 Relative effect of the contact design by velocity of a poorly wetted surface (DLC) in the contact on the coefficient of friction.

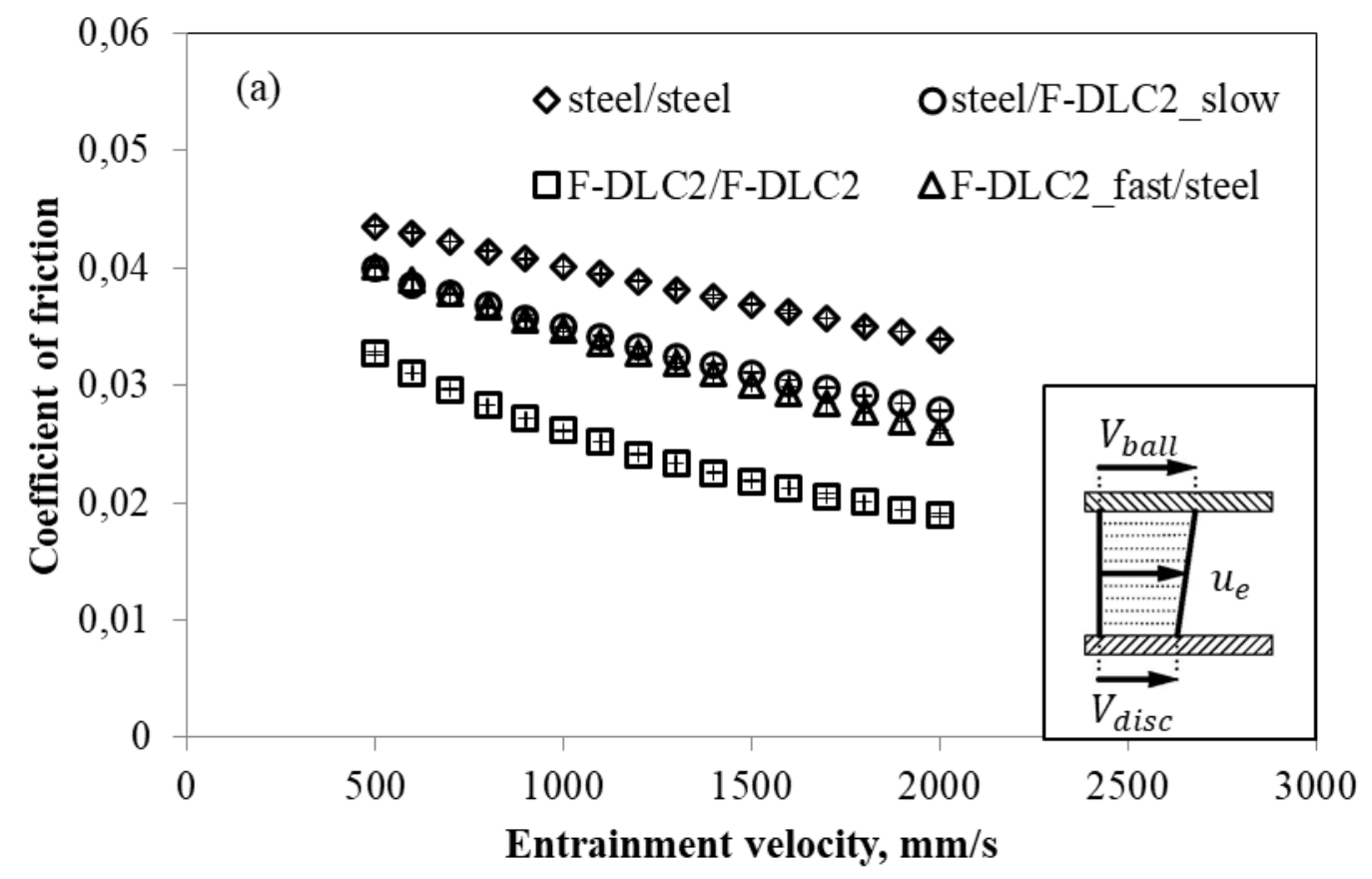


This peer reviewed manuscript has been accepted for publications to the Tribology Letters.

Cite this article as: M. Polajnar, M. Kalin, Effect of the slide-to-roll ratio and the contact kinematics on the elastohydrodynamic friction in diamond-like-carbon contacts with different wetting behaviours, Tribology Letters 60 (2015) 1-10. DOI: https://doi.org/10.1007/s11249-015-0593-3

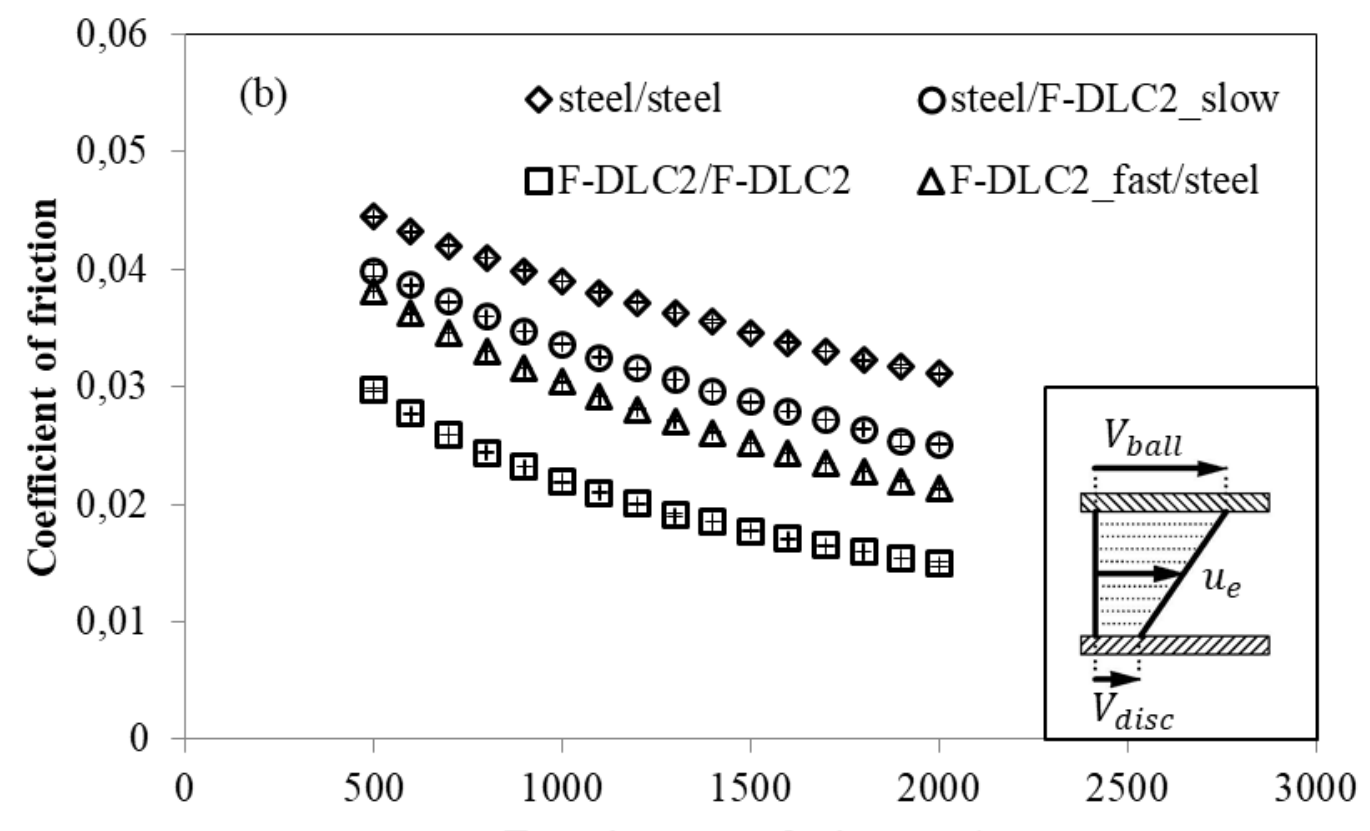

Entrainment velocity, $\mathrm{mm} / \mathrm{s}$

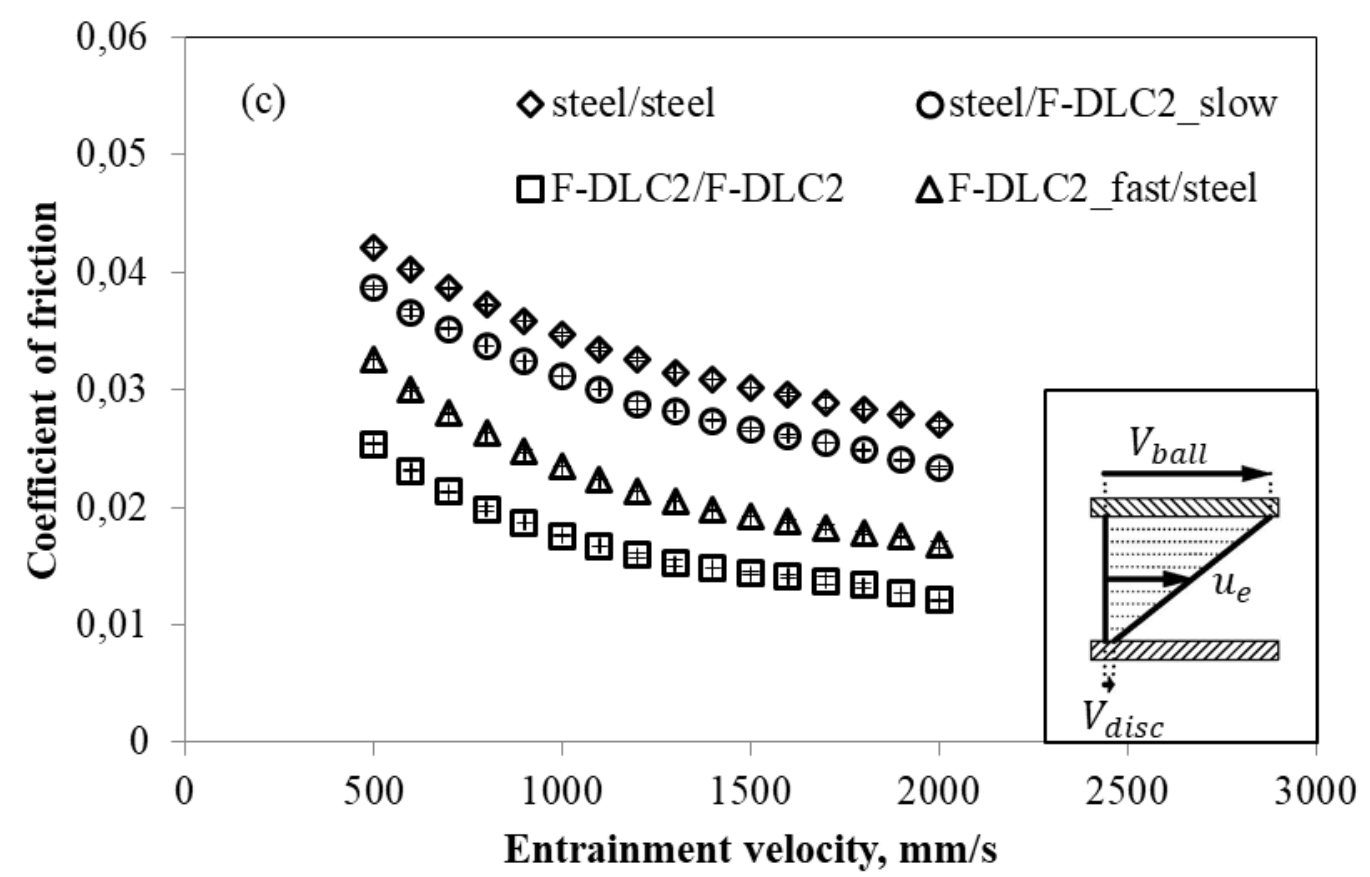

Fig. 9 Coefficient-of-friction results for contacts of F-DLC2 coating at: (a) SRR=-0.5, (b) $\mathrm{SRR}=-1.0$ and (c) $\mathrm{SRR}=-1.8$. The set of results for steel/steel contact is always added as a reference and for a comparison. 
This peer reviewed manuscript has been accepted for publications to the Tribology Letters.

Cite this article as: M. Polajnar, M. Kalin, Effect of the slide-to-roll ratio and the contact kinematics on the elastohydrodynamic friction in diamond-like-carbon contacts with different wetting behaviours, Tribology Letters 60 (2015) 1-10. DOI: https://doi.org/10.1007/s11249-015-0593-3

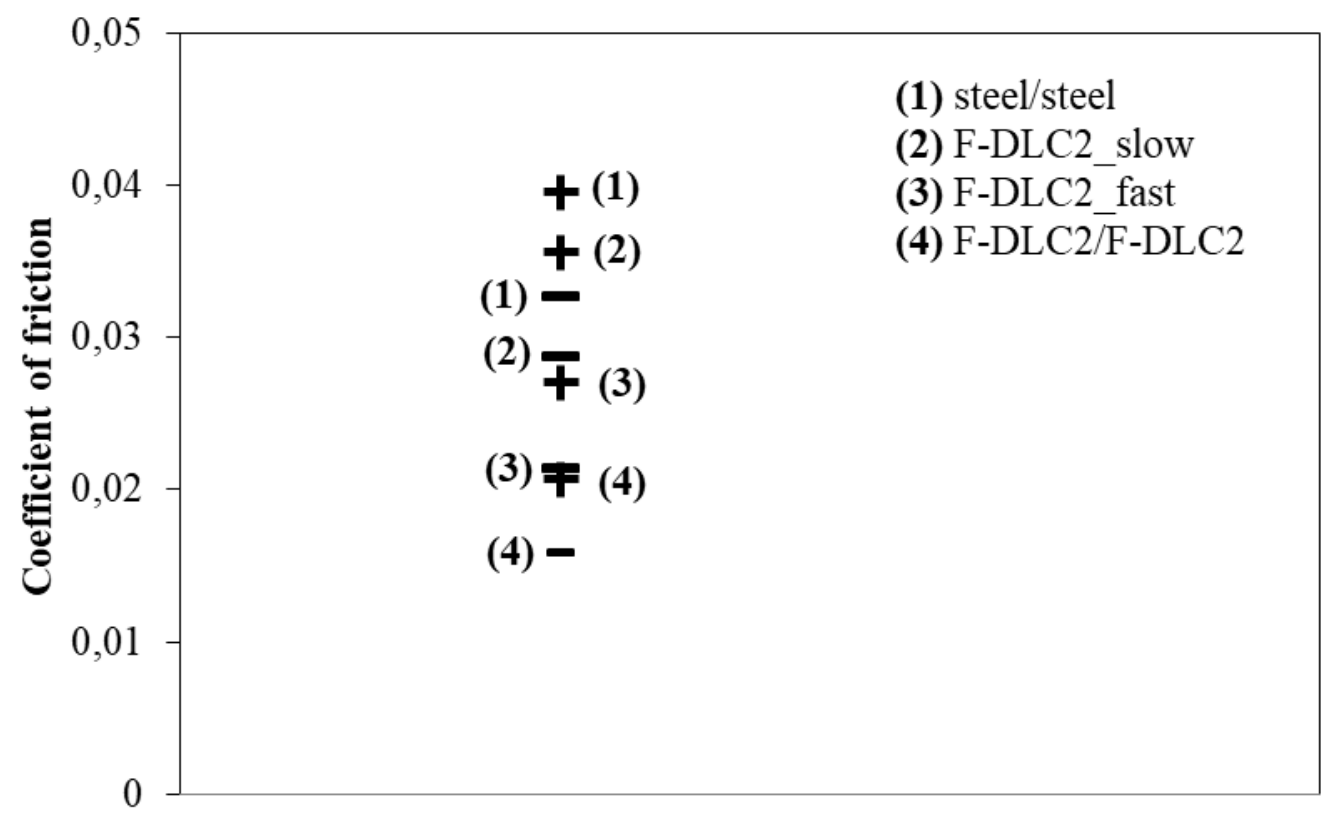

Fig. 10 Coefficient-of-friction results for the same absolute value of $\operatorname{SRR}$ (i.e. $S R R=|1.8|$ ) at entrainment speed of $1200 \mathrm{~mm} / \mathrm{s}$, for different types of contacts studied and for positive (plus sign) and negative (minus sign) value of SRR.

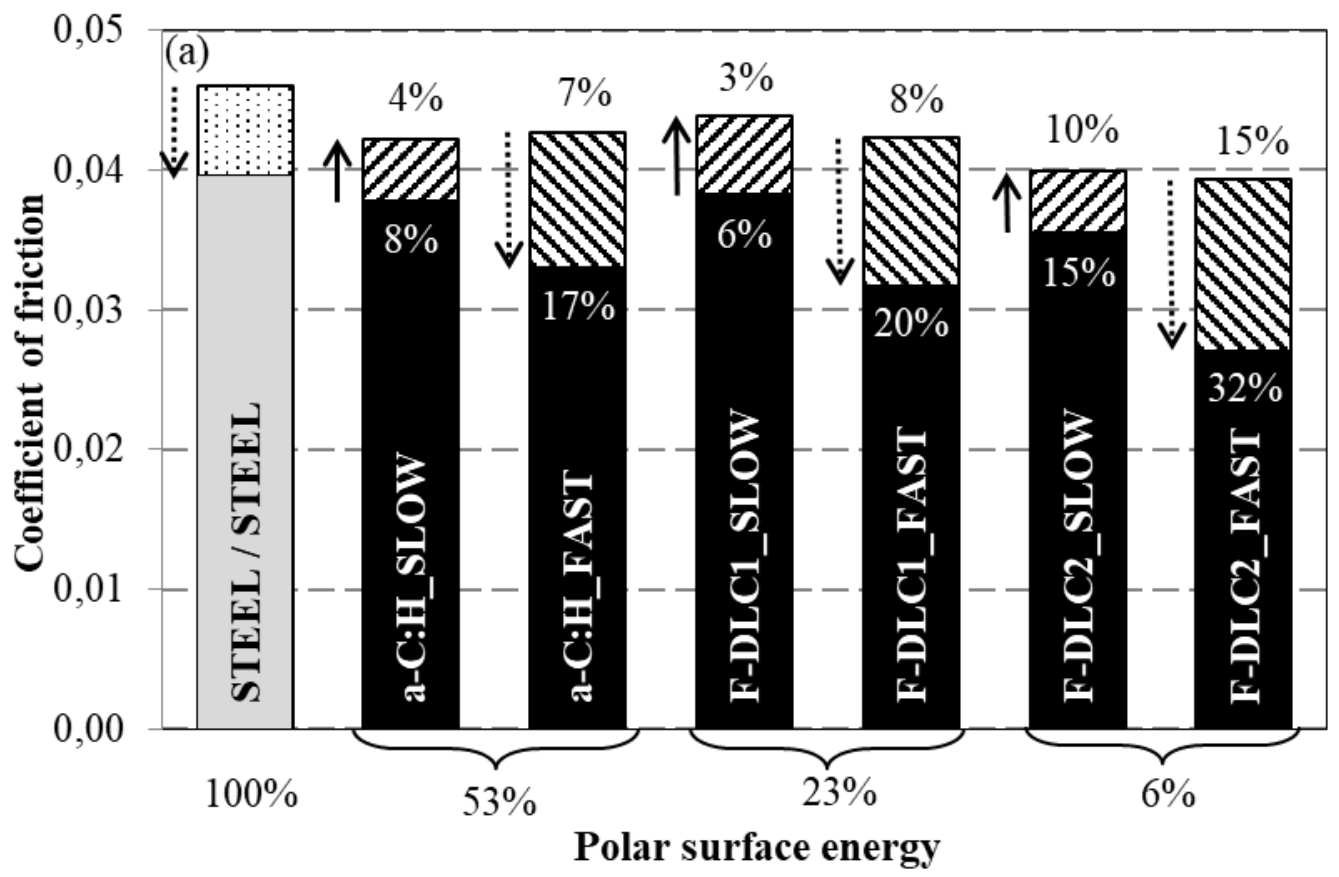


This peer reviewed manuscript has been accepted for publications to the Tribology Letters.

Cite this article as: M. Polajnar, M. Kalin, Effect of the slide-to-roll ratio and the contact kinematics on the elastohydrodynamic friction in diamond-like-carbon contacts with different wetting behaviours, Tribology Letters 60 (2015) 1-10. DOI: https://doi.org/10.1007/s11249-015-0593-3

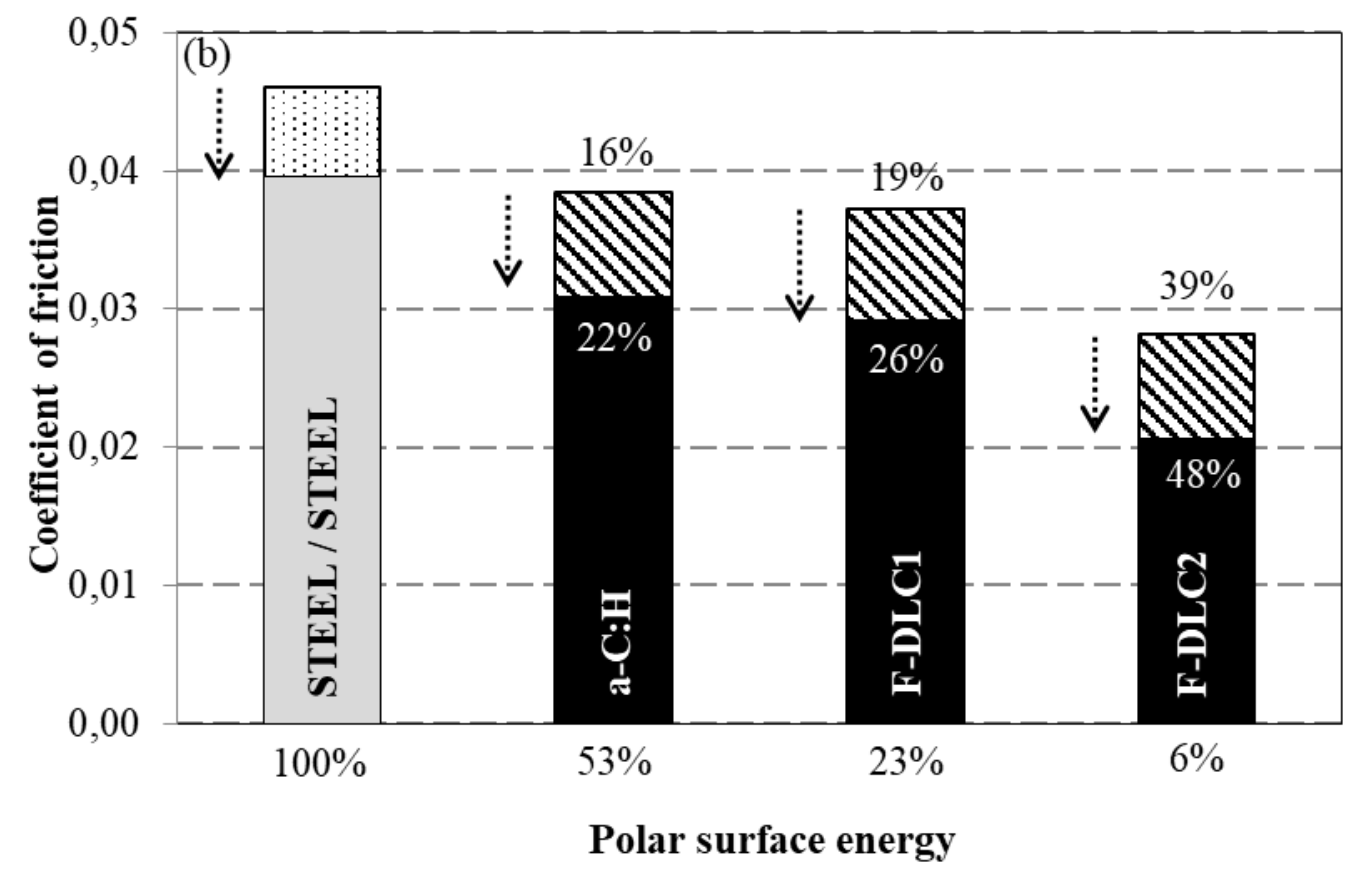

Fig. 11 Range of obtained coefficient-of-friction values for: (a) mixed steel/DLC and (b) selfmated DLC/DLC contacts as a function of wetting (tailored by polar surface energy). Arrows indicate increase/decrease in the coefficient of friction with an increase in the SRR from 0.5 to 1.8. Percentages represent the relative reduction in the coefficient of friction compared to a steel/steel contact. 